\title{
Rock Mechanics and Enhanced Geothermal Systems: A DOE- Sponsored Workshop to Explore Research Needs
}

October 2003

Idaho National Engineering and Environmental Laboratory Bechtel BWXT Idaho, LLC 


\section{Rock Mechanics and Enhanced Geothermal Systems: A DOE-Sponsored Workshop to Explore Research Needs}

Francois Heuze

Peter Smeallie

Derek Elsworth

October 2003

Idaho National Engineering and Environmental Laboratory Idaho Falls, Idaho 83415

Prepared under Subcontract No. 000020377 for the

U.S. Department of Energy

Assistant Secretary for Environmental Management

Under DOE Idaho Operations Office

Contract DE-AC07-99ID13727 


\section{EXECUTIVE SUMMARY}

This workshop on rock mechanics and enhanced geothermal systems (EGS) was held in Cambridge, Mass., on June 20-21 2003, before the Soil and Rock America 2003 International Conference at MIT. Its purpose was to bring together experts in the field of rock mechanics and geothermal systems to encourage innovative thinking, explore new ideas, and identify research needs in the areas of rock mechanics and rock engineering applied to enhanced geothermal systems. The agenda is shown in Appendix A.

The workshop included experts in the fields of rock mechanics and engineering, geological engineering, geophysics, drilling, the geothermal energy production from industry, universities and government agencies, and laboratories. The list of participants is shown is Appendix B.

The first day consisted of formal presentations. These are summarized in Chapter 1 of the report. By the end of the first day, two broad topic areas were defined: reservoir characterization and reservoir performance. Working groups were formed for each topic. They met and reported in plenary on the second day. The working group summaries are described in Chapter 2. The final session of the workshop was devoted to reaching consensus recommendations. These recommendations are given in Chapter 3.

That objective was achieved. All the working group recommendations were considered and, in order to arrive at a practical research agenda usable by the workshop sponsors, workshop recommendations were reduced to a total of seven topics. These topics were divided in three priority groups, as follows.

First-priority research topics (2):

- Define the pre-existing and time-dependent geometry and physical characteristics of the reservoir and its fracture network. That includes the identification of hydraulically controlling fractures.

- $\quad$ Characterize the physical and chemical processes affecting the reservoir geophysical parameters and influencing the transport properties of fractures. Incorporate those processes in reservoir simulators.

Second-priority research topics (4):

- Implement and proof-test enhanced fracture detection geophysical methods, such as 3-D surface seismics, borehole seismics, and imaging using earthquake data.

- Implement and proof-test enhanced stress measurement techniques, such as borehole breakout analysis, tilt-meters, and earthquake focal mechanism analysis.

- Implement and proof-test high-temperature down-hole tools for short-term and longterm diagnostics, such as borehole imaging, geophone arrays, packers, and electrical tools. 
- Improve, validate, and calibrate diagnostic technology for the EGS enhancement process, including tracers for reservoir characterization and heat-exchange diagnostics.

Third-priority research topic (1):

- $\quad$ Establish scaling laws and relationships between laboratory and down-hole measured rock mass properties. 


\section{CONTENTS}

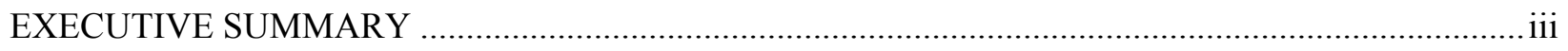

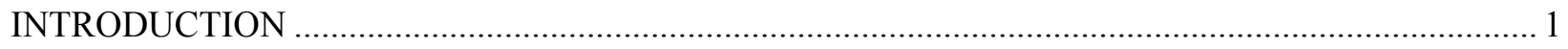

Why ARMA and the Rock Mechanics Community? ............................................................. 1

CHAPTER 1. SUMMARY OF INVITED PRESENTATIONS ....................................................... 2

CHAPTER 2. SUMMARY OF THE WORKING GROUP RECOMMENDATIONS............................ 5

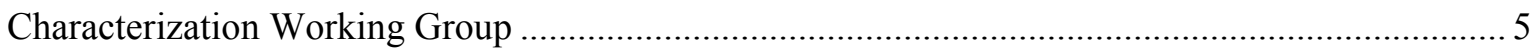

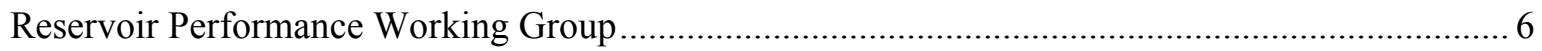

CHAPTER 3. SUMMARY OF THE WORKSHOP RECOMMENDATIONS .................................... 8 


\title{
Rock Mechanics and Enhanced Geothermal Systems: A DOE-Sponsored Workshop to Explore Research Needs
}

\author{
INTRODUCTION
}

DOE's mission in the area of enhanced geothermal systems (EGS) is to develop the technology to produce electricity from engineered geothermal systems. Geothermal energy's contribution to the nation's energy goal of increasing the use of renewable energy technologies will rely on the potential development of EGS. These systems, which allow injected water to be heated and returned to the surface, have been shown to be technically feasible, but large issues remain. The challenge of choosing locales favorable for EGS production and the control of subsurface phenomena is of paramount concern. In addition, given the challenging goal of harnessing this source of energy within a relatively short timeframe, the development of new, revolutionary technologies or the application of existing but non-generic technologies should be addressed.

In the development of any plans for exploiting EGS, rock mechanics and rock engineering issues are of considerable import. What are the geological conditions suitable for EGS? What is the state of knowledge in rock mechanics/rock engineering required for EGS? How create permeability in the subsurface? The workshop brought together a distinguished group of experts to address these and other pertinent issues.

\section{Why ARMA and the Rock Mechanics Community}

The rock mechanics and rock engineering fields have a long association with the conditions encountered in EGS environments. Rock engineers have long recognized the role that fracture geology and fracture geometry play in potentially harnessing new geothermal systems.

The contributions of rock mechanics to the field of fractures and fluid flow have been evident in two major efforts of the National Research Council. In 1996, the U.S. National Committee for Rock Mechanics released Rock Fractures and Fluid Flow: Contemporary Understanding and Applications, a detailed report on tools and techniques of understanding rock fractures. In 2001, the same committee issued Conceptual Models of Flow and Transport in the Fractured Vadose Zone, a description of the processes through which conceptual models of flow and transport in the fractured vadose zone are developed, tested, refined, and reviewed.

In practice, the rock mechanics community has always been interdisciplinary. The American Rock Mechanics Association (ARMA), a professional society, provides a forum for the exchange of rock mechanics and rock fracture information among civil engineers, mining engineers, petroleum engineers, and geologists. Hence, ARMA offers a capability for drawing on multidisciplinary resources to address problems of flow and transport in fractured rock.

The ARMA Foundation, a 501-(C)-3 organization, is a parallel organization to the membershipbased ARMA and was established to undertake research and educational activities to elevate the level of understanding of rock mechanics. The ARMA Foundation has received grants and contracts from the National Science Foundation, the Air Force Office of Scientific Research, and numerous corporate contributions. 


\section{CHAPTER 1. SUMMARY OF INVITED PRESENTATIONS}

Presentations consisted of information from several geothermal fields around the world, such as: Soultz in France, Hijiori in Japan, Rosemanowes in the United Kingdom, Fenton Hill in the United States, and Lardarello in Italy. ${ }^{a}$

Dr. Sylvie Gentier of the Bureau de Recherches Geologiques et Minieres (BRGM), Orleans, France, gave a presentation titled, "Thermo-Hydro-Mechanical (THM) Mechanisms Involved in the Hydraulic Stimulation of Deep Geothermal Wells." It was based on recent and continuing studies at the Soultz geothermal site in France. Her conclusions are summarized as:

- $\quad$ Fractures occurred both as isolated features and as clusters.

- There was insufficient hydraulic connectivity around the well, thus requiring hydraulic stimulation.

- $\quad$ Rock cooling induced micro-fractures of the rock material.

- $\quad$ Only some of the fractures zones responded to stimulation.

- $\quad$ THM modeling based on in situ tests and with adequate geological data reproduced the flowpressure response of the hydraulic stimulation.

Professor Daniel Swenson of Kansas State University gave a presentation, co-authored by Professor Takahashi Ito of Tohoku University, Sendai, Japan titled, "Coupled Effects on Flow and ShortCircuiting in EGS Systems." It was based on studies performed at the Hijiori geothermal reservoir in Japan from 2000 through 2002. Their conclusions are summarized as follows:

- Micro-seismic events indicated the extent of stimulation and were used to help connect wells.

- $\quad$ Tracers showed a very dynamic (evolving) reservoir. They provided estimates of flow paths and fluid volumes, as well as warnings of short-circuits.

- Thermally degrading tracers can be use to estimate a "characteristic" temperature.

- The Hijiori reservoir was relatively closed at low injection pressures and open at high injection pressures

- Hydraulic stimulation activates pre-existing fractures.

- $\quad$ All fractures are initially permeable, but chemical reactions tend to seal them; only the active fractures remain open.

- Knowing the reservoir stress state permits prediction of required stimulation pressures and can be used to predict the orientation of permeable fractures.

- $\quad$ EGS systems use re-injection as part of their standard operation. This means that relatively cold water will be injected into the system.

a. The full set of invited presentations is posted on the ARMA Web site (www.armarocks.org). For reasons of practicality, only summaries of these presentations are given in this report. 
- $\quad$ There are fundamental conflicts in geothermal reservoir exploitation, such as high flow rates versus thermal breakthrough and well spacing versis connection and flow rates.

- Thermal contraction has both positive effects, such as increased flow due to increased aperture, and negative effects, such as potential short-circuiting.

- $\quad$ Several codes are currently under development for hydro-thermo-mechanical analysis.

- Tools that help in dealing with the EGS challenge are micro-seismics, tracers, and stress state analysis.

- One needs active methods to control flow, because it appears that the physics of natural systems is unstable. Cold flow through dominant fractures further opens these fractures by thermal contraction. That leads to short-circuiting.

Professor Derek Elsworth of Pennsylvania State University gave a presentation titled, "Hydromechanical and Hydrochemical Influences on the Transport Properties of Fractured Reservoirs." The presentation reflected cooperation between Penn State and the University of Western Australia. Its conclusions are summarized as follows:

- The strong influence of stress and precipitation/dissolution processes in the evolution of permeability in fractured reservoirs is well known. However, field results from existing HDR circulation tests show a surprising insensitivity to these stress- and chemistry-mediated changes in permeability in the thermal draw-down record, once the reservoir has been initially stimulated.

- $\quad$ These effects are apparent for both blocky (Rosemanowes, UK) and single-fracture dominated (Fenton Hill, USA) reservoirs, and suggests that the form of the initially developed reservoir exerts a strong, and perhaps overriding, control on long-term thermal performance.

- $\quad$ The form of the initial reservoir stimulation is critically important and sets the form for the longterm development of the reservoir. This behavior is strongly conditioned by relatively fast-acting mechanical and chemical effects that are incompletely understood.

- $\quad$ Coupled mechanical and chemical effects, even at modest temperatures $\left(80^{\circ} \mathrm{C}\right)$ and stresses (3.5 MPa) may result in fast (order of days to weeks) and significant (multiple orders of magnitude) changes in fracture permeability.

- Fractures may gape or seal, even under conditions of net dissolution anticipated in most reservoirs, with concomitant increases or reductions in reservoir permeability. Net dissolution may result in permeability decrease.

- $\quad$ Reservoir permeabilities depend critically on the local stress, chemical potential, and thermal paths followed within the reservoir with these effects influencing the initial stimulation and potentially the untested long-term performance. The challenge remains in understanding, characterizing, and predicting these influences, prior to reservoir development.

Professor Nafi Toksoz of the Massachusetts Institute of Technology presented a talk, co-authored by Michael Fehler of Los Alamos National Laboratory, and titled, "Reservoir Characterization Using Surface Seismic and Induced Earthquake Data." He described several seismic methods and showed how some of them had been used at the Lardarello geothermal field in Italy. His conclusions were that: 
- $\quad$ Seismic methods can produce detailed images and properties of geothermal reservoirs.

- $\quad$ Seismic data from 3-D surface surveys, vertical seismic profiling, seismic while drilling, and local earthquakes can be used to determine reservoir geometry and fluid distribution.

- Data from natural and induced earthquakes recorded by a local seismic network are a cost-effective approach to geothermal reservoir characterization.

Professor Jack Hermance of Brown University made a presentation titled, "Exploring, Characterizing, Monitoring, and Managing Geothermal Systems - Application of Surface and Down-Hole Geophysics." He described the types of high-temperature regimes: fluid-dominated, vapor-dominated, and dry. He then described the toolbox of geophysics (seismic, electromagnetic, and electrical methods) including standard logging tools and far-field sensing borehole tools. He identified the physical information recovered from geophysical surveys, and finally concluded with the following recommendations:

- Apply geophysics to EGS characterization.

- Improve high-temperature borehole logging techniques.

- $\quad$ Develop far-field borehole sensing methods.

Dr. Sydney Green of TerraTek in Salt Lake City, Utah, gave a talk titled, "Rock Mechanics Requirements for Enhanced Geothermal Systems." He described a number of areas of rock mechanics requiring additional development as:

- Determination of thermo-mechanical properties and relative permeability of reservoir rocks.

- Determination of the hydraulic conductivity of fractures.

- Development of better methods for fracture mapping.

- Determination of in situ stresses.

- $\quad$ Scaling from laboratory-size samples to field scales.

Dr. Green also offered the following comments regarding EGS:

- $\quad$ Basic rock mechanics understanding is not in place but is required for all phases of EGS development.

- $\quad$ Field programs will require large funding and should be carefully justified when there are very limited budgets.

- $\quad$ Large-scale laboratory tests are an essential step between (normal) laboratory tests and field tests.

- Continuous flow EGS will be very difficult to make "work" economically. 


\section{CHAPTER 2. SUMMARY OF THE WORKING GROUP RECOMMENDATIONS}

\section{Characterization Working Group}

The recommendations of that panel were grouped in four categories:

1. Characterizing the existing fracture network

2. Thermal, hydrological, mechanical, and chemical properties of the rock mass

3. Determining stress direction and magnitude

4. Diagnostics during reservoir operation, and calibrating the reservoir processes model.

\section{Characterizing the Existing Fracture Network}

- Improve and demonstrate seismic methods directed to fracture characterization. Use 3-D, 3-component surface seismics, borehole seismics, and imaging using earthquake data.

- Improve and demonstrate electromagnetic and resistivity methods for surface, borehole, and surface-to-borehole applications.

- Current barriers are:

- $\quad$ Lack of knowledge of relevant rock mass properties

- $\quad$ Lack of effective laboratory-to-field scaling laws

- $\quad$ Difficulty with handling lateral heterogeneity.

\section{Thermal, Hydrological, Mechanical, Electrical, and Chemical Properties of the Rock Mass}

Ascertain the thermal, hydrological, mechanical, electrical, and chemical properties of the rock mass.

- Current barriers are:

- $\quad$ Stress-induced anisotropy of the mechanical properties

- $\quad$ Lack of effective laboratory-to-field scaling laws

- $\quad$ Disturbance due to drilling and core recovery.

\section{Determining Stress Direction and Magnitude}

- $\quad$ Enhance and demonstrate appropriate methods for borehole break-outs, cross-dipole logging, micro-earthquake focal mechanisms, shear-wave splitting, tectonic analyses, and mini-fracs.

- $\quad$ Current barrier is:

- $\quad$ Understanding the effects of high thermal gradients. 


\section{Diagnostics During Reservoir Operation, and Calibrating the Reservoir Processes Model}

- $\quad$ Demonstrate and proof-test geophysical methods, tracer methods, well-test methods, and fluid sampling methods for geochemistry.

- $\quad$ Current barriers are:

- $\quad$ Paucity of proven high-temperature instrumentation

- $\quad$ Lack of coupling between diagnostics and predictive models.

\section{Reservoir Performance Working Group}

This working group arranged its findings along the following five topics:

1. Spatial hierarchy

2. Flow paths

3. Well-log data

4. Tracers and detectors

5. Creation and active control of reservoir.

\section{Spatial Hierarchy}

- Create, calibrate, and validate models from micro to macro

- Understand regional geologic features and stresses to predict expected flow paths

- Understand which of the fractures will contribute to flow.

\section{Flow Paths}

- How is micro-seismic information related to flow?

- How do flow paths change with time?

- How do thermal effects change the flow?

\section{Well-Log Data}

- $\quad$ Proof-test methods to determine geothermal reservoir rock properties from conventional log data.

- Use borehole methods for imaging fractures.

- Develop models for fracture deformability and validate with borehole imaging. 


\section{Tracers and Detectors to Identify Processes in the Reservoir}

- $\quad$ Use reactive and non-reactive tracers.

- $\quad$ Do real-time measurements of tracer signals from individual fractures.

- $\quad$ Establish the consistency of multiple tracer measurements.

\section{Creation and Active Control of the Reservoir}

- Use "enlightened empiricism;" be flexible in the response to observed behavior.

- $\quad$ Employ re-drilling.

- $\quad$ Attempt blocking of selected flow paths.

- Use chemical stimulation. 


\section{CHAPTER 3. SUMMARY OF THE WORKSHOP RECOMMENDATIONS}

All the working group recommendations were considered and, in order to arrive at a practical research agenda usable by the workshop sponsors, workshop recommendations were reduced to a total of seven topics. These topics were divided in three priority groups, as follows.

First-priority research topics (2):

- $\quad$ Define the pre-existing and time-dependent geometry and physical characteristics of the reservoir and its fracture network. That includes the identification of hydraulically controlling fractures.

- $\quad$ Characterize the physical and chemical processes affecting the reservoir geophysical parameters and influencing the transport properties of fractures. Incorporate those processes in reservoir simulators.

Second-priority research topics (4):

- Implement and proof-test enhanced fracture detection geophysical methods, such as 3-D surface seismics, borehole seismics, and imaging using earthquake data.

- Implement and proof-test enhanced stress measurement techniques, such as borehole breakout analysis, tilt-meters, and earthquake focal mechanism analysis.

- Implement and proof-test high-temperature down-hole tools for short-term and long-term diagnostics, such as borehole imaging, geophone arrays, packers, and electrical tools.

- Improve, validate, and calibrate diagnostic technology for the EGS enhancement process, including tracers for reservoir characterization and heat-exchange diagnostics.

Third-priority research topic (1):

- $\quad$ Establish scaling laws and relationships between laboratory and down-hole measured rock mass properties. 


\section{Appendix A}

Rock Mechanics and Enhanced Geothermal Systems:

A DOE-Sponsored Workshop to Explore Research Needs 


\section{Appendix A}

\section{Rock Mechanics and Enhanced Geothermal Systems: A DOE-Sponsored Workshop to Explore Research Needs}

\section{Working Agenda - June 20-21, 2003, Cambridge, MA}

\section{Friday p.m.-Hotel at MIT, 20 Sidney Street, Cambridge}

- Welcome, Introductions, Workshop Overview 1:00-1:30

Welcome participants:

DOE perspective:

Purpose of workshop:

Overview of process:

Participant introductions (Name, organization)
Peter Smeallie

Joel Renner/Allan Jelacic

Francois Heuze

Robin Amadei

- Invited Presentations

1:30-4:00

Presenters:

- $\quad$ Sylvie Gentier, Thermo-Hydro-Mechanical Mechanisms Involved in the Hydraulic Stimulation of Deep Geothermal Wells

- Daniel Swenson, Thermal Effects on Flow and Short-Circuiting in EGS Systems

- Derek Elsworth, Hydromechanical and hydrochemical influences on the transport properties of fractured reservoirs

- $\quad$ Nafi Toksoz, Reservoir characterization using surface seismic and induced earthquake data

- $\quad$ Jack Hermance, Remote sensing methods for rock mass characterization

20-minute presentations, 10 minute discussion after each presentation

- $\quad$ Participant presentations

"From your perspective, in order of priority, what are the three principal areas in which research should be undertaken?"

3-5 minute presentations (one viewgraph each)

- $\quad$ Formation of working groups for Saturday

Tentative working groups:

- Imaging the reservoirs, geology and geomechanics

- Understanding processes: thermal, hydraulic, mechanical, and chemical

- Identifying how to improve the technologies to harness geothermal power from artificially created geothermal systems

- Others?

- $\quad$ Adjourn for day 


\section{Saturday a.m.-Bldg. 1-246, MIT}

$\begin{array}{ll}\text { - Convene participants } & \text { 8:00 }\end{array}$

$\begin{array}{ll}-\quad \text { Invited presentation: Sidney Green } & \text { 8:00-8:30 }\end{array}$

20-minute presentation, 10-minute discussion

- Work groups:

8:30-10:30

Propose research topics for a three-year time period. Be ready to report back those research ideas, your rationale, and your approach to such research.

- $\quad$ Break 10:30-10:45

- Group reports to plenary

15 minutes per group, with 15-minute discussion after each group presentation

- Lunch 12:15-1:30

\section{Saturday pm}

- DOE comments on progress thus far

- Work groups:

$1: 45-3: 30$

Create a research project action plan. Outline a proposal to be incorporated in draft report. Consider: what, when, where, how, etc.

- $\quad$ Break 3:30-3:45

- $\quad$ Report back to plenary

- Closing statements

DOE

Francois Heuze

- $\quad$ Adjourn

5:00 


\section{Appendix B Workshop Participants}




\section{Appendix B}

\section{Workshop Participants}

Francois E. Heuze, Workshop Chairman

President, American Rock Mechanics

Association

Leader, Geotechnical Projects, L-200

Lawrence Livermore National Laboratory

Livermore, CA 94551

925.423.0363; Fax: 925.423.6907

heuze@llnl.gov

Allan Jelacic, Workshop Sponsor Office of Geothermal Technologies U.S. Department of Energy, Room 5H040 1000 Independence Avenue, S.W. Washington, DC 20585

202.586.6054; Fax: 202.586.8185

allan.jelacic@hq.doe.gov

Joel Renner, Workshop Sponsor

Geothermal Program Manager

Idaho National Engineering and

Environmental Laboratory

PO Box 1625; MS 3830

2525 North Fremont

Idaho Falls, ID 83415

208.526.9824; Fax: 208.526.0969

rennerjl@inel.gov

Peter Smeallie, Project Manager

Executive Director

American Rock Mechanics Association

600 Woodland Terrace

Alexandria, VA 22302

703.683.1808; Fax: 703.683.1815

Smeallie@armarocks.org

Robin Amadei, Workshop Facilitator

Commonground

2536 Columbine Circle

Lafayette, CO 80026

303.604.1960; Fax: 303.604.6278

ramadei@aol.com
Ahmed Abou-Sayed

President / CEO

Advantek International Corporation

3300 S. Gessner \# 257

Houston, TX 77063

713. 532.7627

ahmedas@advantekinternational.com

Chad Augustine

Graduate Student

Chemical Engineering Department

Massachusetts Institute of Technology

Building 66, Room 053

Cambridge, MA 02139

617.253.6444

augie@mit.edu

Greg Boitnott

New England Research, Inc.

331 Olcott Drive; Suite L-1

White River Junction, VT 05001

802.296.2401; Fax 802.296.8333

boitnott@ner.com

Robert Lee Cardenas

Project Engineer

Foster-Miller

350 Second Avenue

Waltham, MA 02451

781.684.4283; Fax: 781.684.3959

bcardenas@foster-miller.com

Benjamin Dolgin

Chief Scientist

UTD Incorporated

8350 Alban Road Suite 700

Springfield, VA 22150

703.440.8834; Fax 703.455.4675

BDolgin@UTDinc.com 
Herbert H. Einstein

Professor, Dept. of Civil Engineering

Bldg. 1-342

Massachusetts Institute of Technology

77 Massachusetts Avenue

Cambridge, MA 02139

617.253.3598; Fax: 617.253.6044

einstein@mit.edu

Derek Elsworth

Treasurer, American Rock Mechanics

Association

Professor

Pennsylvania State University

221 Walker Building

University Park, PA 16802

814.865.2225; Fax: 814.863.7809

elsworth@psu.edu

Sylvie Gentier

BRGM/CDG/Geo-Energy Unit

3 Avenue C. Guillemin

45060, Orleans, Cedex 2

France

s.gentier@brgm.fr

Sidney J. Green

President, TerraTek, Inc.

400 Wakara Way

Salt Lake City, UT 84108

801.584.2401; Fax 801.584.2406

sgreen@terratek.com

Bezalel C. Haimson

Dept. of Materials Science and Engineering

University of Wisconsin-Madison

1509 University Avenue

Madison, WI 53706

608.262.2563; Fax: 608.262.8353

bhaimson@wisc.edu

John F. Hermance

Environmental Geophysics/Hydrology

Department of Geological Sciences

Brown University

324 Brook Street

Providence, RI 02912-1846

401.863.3830; Fax: 401.863.2058

john hermance@brown.edu
Violeta M. Ivanova, Ph.D.

Board Member, ARMA

8200 Neely Drive, \# 247

Austin, TX 78759

512.342.9746

vmivanova@alum.mit.edu

Paul Kasameyer

Applied Geophysics Group

Energy and Environment Directorate

Lawrence Livermore National Laboratory

Livermore, CA 94551

925.422.6487

kasameyer1@|lnl.gov

B. Mack Kennedy

Center for Isotope Geochemistry

MS 70A-4418

Lawrence Berkeley National Laboratory

Berkeley, CA 94720-8179

510.486.6451; Fax: 510.486.5496

bmkennedy@lbl.gov

Susan Petty

Black Mountain Technology

3679 Bozeman Drive

Reno, NV 89511

775.852 .6398

Cell. 775.846.0803; Fax 775.852.0458

susanpetty@aol.com

Ann Robertson-Tait

Senior Geologist

GeothermEx, Inc.

5221 Central Ave., Suite 201

Richmond, CA 94804

510.527.9876; Fax: 510.527.8164

mw@geothermex.com

Peter E. Rose, Ph.D.

Geothermal Program Coordinator

Energy \& Geoscience Institute

Research Assistant Professor

Dept of Chemical and Fuels Engineering

University of Utah

423 Wakara Way suite 300

Salt Lake City, UT 84108

801.585.7785

prose@egi.utah.edu 
Daniel Swenson

Thunderhead Engineering Consultants, Inc. 1006 Poyntz Avenue

Manhattan, KS 66502-5459

785.770.8511; Fax: 785.770.8511

swenson@thunderheadeng.com

Jeff Tester

Professor, Chemical Engineering

Massachusetts Institute of Technology

Building 66, Room 454

Cambridge, MA 02139

617.253.7090

testerel@mit.edu

Nafi Toksoz

Professor, MIT Earth Resources Lab

Massachusetts Institute of Technology

Building E-34, Room 440

Cambridge, MA 02139

617.253.7852; Fax: 617.253.6385

toksoz@mit.edu
Herbert F. Wang

Professor, Department of Geology and Geophysics

University of Wisconsin

1215 W. Dayton Street

Madison, WI 53706

608.262.5932; Fax 608.262.0693

wang@geology.wisc.edu

Norm Warpinski

Senior Scientist

MS 0750; PO Box 0750

Sandia National Laboratories

Albuquerque, NM 87185

505.844.3640; Fax: 505.844.7354

nrwarpi@sandia.gov 